7 Hypertension Detection and Follow-up Program Cooperative Group. Five-year findings of the hypertension section and follow-up program 1. Reduction in mortality of persons with

8 Management Committee. The Australian therapeutic trial in mild hypertension. Lancet 1980;i:1261-7.

Bulpitt CJ, Daymond MJ, Dollery CT. Community care compared with hospital outpatient care for hypertensive patients. $\mathrm{Br} \mathrm{Med} \mathcal{F} 1982 ; \mathbf{2 8 4}: 554-6$.

$10 \mathrm{Hart} \mathrm{JT}$. The management of high blood pressure in general practice. $f \mathrm{R}$ Coll Gen Pract 1975;25:160-92.

11 Heller RF, Rose G. Current management of hypertension in general practice. Br Med' $f$ 1977; i: 1442-3

12 Ritchie LD, Currie AM. Blood pressure recording by general practitioners in north-east Scotland. Br Med f 1983;286:107-9.
13 Heller RF, Rose G. Current management of hypertension in hospital. Br Med $\mathcal{f}$ 1977; : 1441-2.

14 Beilin LJ, Bulpitt CJ, Coles EC, et al. Long-term antihypertensive drug treatment and blood pressure control in three hospital hypertension clinics. $\mathrm{Br} H$ eart $f$ $1980 ; 43: 74-9$.

15 Curzio J. Monitoring hypertension. Nursing Times 1983;559-61.

16 Kelman A, Reid JL, Rubin PC. BP: A microcomputer program for use in a hypertension clinic. Computer Programs in Biomedicine 1982;14:185-90.

17 Coope J. Hypertension in general practice: what is to be done? $\mathrm{Br}$ Med $\mathcal{F} 1984$ 288:880-1.

18 Memorandum from a WHO/ISH meeting. Guidelines for treatment of mild hypertension $1983 ; 5: 395-7$.

(Accepted 15 fune 1984)

\title{
Motor neurone disease: can we do better? A study of 42 patients
}

\author{
P G NEWRICK, R LANGTON-HEWER
}

\begin{abstract}
A feeling that patients with motor neurone disease were not always well managed prompted a study of the symptoms, functional levels, and use of aids in a group of 42 patients. Pain, falls, constipation, and swelling of the legs emerged as the major symptomatic problems. At the time of assessment two thirds of the patients appeared to be in need of aids which had not been provided. Disturbance of sleep secondary to positional nocturnal discomfort caused much distress to both the patient and spouse; and this might be eased by the use of an electric turning bed. Over half the patients said that they disliked attending neurology outpatient clinics. Criticism centred on poor transport arrangements, lack of information about the control of symptoms, and unsatisfactory help from junior staff. A key worker should be identified as part of a new strategy for managing these patients.
\end{abstract}

\section{Introduction}

"He is no more use to me than the milkman." The writer was a patient with motor neurone disease who almost certainly did not intend to belittle the important role of the milkman in our society but who felt that his neurologist could have been more helpful. His statement and our experience prompted us to a closer examination of symptoms and practical problems in motor neurone disease. There are several reviews of management of motor neurone disease ${ }^{-6}$ and articles on specific aspects such as cricopharyngeal myotomy, ${ }^{7}$ palatal prostheses, ${ }^{8}$ and ventilator care. ${ }^{9}$ None of the published work, however, gives clear guidance about the frequency and management of common symptoms and practical problems. We designed our study to provide factual information which might form the basis for an improved pattern of care.

Department of Neurology, Frenchay Hospital, Bristol BS16 1LE P G NEWRICK, MB, MRCP, medical registrar

R LANGTON-HEWER, MB, FRCP, consultant neurologist

Correspondence to: Dr R Langton-Hewer.

\section{Patients and methods}

Forty five patients with a definite diagnosis of motor neurone disease were identified from the diagnostic indices of three consultant neurologists in two units (30 from the Department of Neurology, Bristol were under the care of R L-H and 15 were from the Wessex Neurological Unit, Southampton). A letter was initially written to the patient asking if he would be willing to be interviewed by a doctor who had a particular interest in his condition. One of us (PGN) conducted a single interview with 42 of the patients (two patients had died before being seen and in one case the general practitioner felt that his patient should not be approached). Twenty five were interviewed in their homes with the spouse and the remainder in various hospital departments. Two were inpatients at the time of interview.

The interview was conducted in an open unhurried fashion with the objective of trying to allow problems to emerge readily. It was unstructured in that the wording of the questions was not specified. Nevertheless, the interviewer did have a checklist, which was not visible to the patient. Specific questions were asked, to assess the following:

Duration of symptoms and interval before diagnosis

Duration of independence or otherwise-We accepted the views of patients and their families on the duration of independence and did not seek to categorise them by an interpretation of their problems.

Disability-Disability was assessed on performance in three aspects, with a new scale. A new scoring system is justified because there are no scales designed specifically for use in motor neurone disease. Of the numerous indices of activities of daily living, ${ }^{10}$ most of the existing scales relate to cerebrovascular disease, do not include bulbar disability, and are time consuming in practical use. Functional staging in motor neurone disease $\mathrm{e}^{5}$ does not allow for the variation in severity between bulbar and limb disorder in the same patient. A scale for dysarthria and bulbar problems requires special skills in use. ${ }^{11}$ With our scale bulbar function, limb function, and sources of patient care were scored out of a total of 25 points (see Appendix). The normal person would score 25 . Bulbar function (max score 7 ) was assessed on swallowing, drooling, and speech. Arm function (max score 7) was largely concerned with self care and was scored on ability to dress, bath, and manage to use the lavatory. Leg function (max score 8) was assessed on the different aspects of mobility: walking, managing stairs, and transfer from a bed to a chair. Arm and leg function were linked together as a total limb score (max score 15). The sources of patient care were recorded (max score 3 ) because this is a guide to overall function-for example, whether the patient coped with help from the family alone or relied on outside help or regular holiday relief. The scale is not designed to bring out the element of time and effort the disabled person must expend in comparison with normal but rather to delineate severe from moderate or mild disability. 
Details of symptoms - The patients were asked not only about the "standard" neurological symptoms such as fasciculation, fatigue, dysphagia, and limb spasms but also about problems that our experience has led us to believe might be easily missed but be of great practical importance. These latter included troubled sleeping, pain, bowel disturbance, and anything else that the patient or family cared to mention. We sought to determine the nature, frequency, and severity of as many symptoms and problems as possible.

Views on the neurology clinic-Patients were asked, in a strictly neutral manner, about their experience with neurology outpatient departments.

Use, adequacy, and availability of aids-The patients and family were asked what aids were in use and how effective they were. We recorded the absence of aids which, in the opinion of the interviewing doctor, were desirable even if the patient were unaware of the possibilities.

Housing-The type of house, location of the lavatory, need to use the stairs, and access to the house from outside were recorded.

\section{Results and comment}

\section{PATIENTS}

Table I shows details of the patients. The mean time to diagnosis was surprisingly long. This was due partly to the long delay before general practitioner referral to a consultant, often because the patients were labelled as "aging," rheumatic, or parkinsonian. No patient appeared to come to harm as a result of diagnostic delay. The mean duration of symptoms was long but was skewed by the inclusion of 10 patients with slowly progressive motor neurone disease for over 60 months; three of these had had symptoms for over 120 months. The median duration of symptoms was 29 months and 16 patients had symptoms for less than 24 months.

TABLE I-Details of 42 patients with motor neurone disease

\begin{tabular}{lll}
\hline & Men & Women \\
\hline No & 27 & 15 \\
Mean age (SE) & $62(2 \cdot 4)$ & $65(1.58)$ \\
Age range & $37-86$ & $57-76$ \\
Mean time to diagnosis (months (SE) & $22(6 \cdot 26)$ & $24(7.02)$ \\
Mean duration of symptoms (months) (SE) & $45(7 \cdot 75)$ & $39(8.04)$ \\
\hline
\end{tabular}

\section{FUNCTIONING}

The extent of disability was analysed in terms of specific problems (table II). Anarthria was defined as speech which was unintelligible even to those closest to the patient. The patients were categoriesd in terms of being independent or partially or totally dependent. Of the $\mathbf{4 2}$ in our series, 20 were independent as judged by themselves and families, 14 were partially dependent, and eight were totally dependent. Eighteen of the 20 judged independent scored $20-25$ on our 25 point scale and all eight totally dependent patients scored under 10 . The extra two patients with no contribution to self care (table II) retained some mobility but had useless arms.

TABLE II-Functional status of 42 patients with motor neurone disease

\begin{tabular}{lcc}
\hline Problem & No $\left({ }_{0}\right)$ & $\begin{array}{c}\text { No }\left({ }_{0}^{\circ}\right) \text { of partially } \\
\text { and totally dependent } \\
\text { patients }(22)\end{array}$ \\
\hline Anarthria & $10(24)$ & $19(46)$ \\
Continuous drool & $8(20)$ & $15(36)$ \\
Regular choking & $7(17)$ & $13(32)$ \\
Chair bound & $11(26)$ & $21(50)$ \\
Bed bound & $3(7)$ & $6(14)$ \\
No contribution to self care & $10(24)$ & $19(46)$ \\
\hline
\end{tabular}

Patients were also grouped by disability (table III). This provided a guide to the neurology departments' workload and showed that at any one time roughly a half had bulbar symptoms or definite problems with mobility, or both, and a third had severe global disability. This last group are the "hard core" and are likely to require the greatest input of services.

\section{SYMPTOMS}

Symptoms were varied and multiple and it is not feasible to discuss them all. Table IV shows those most often identified. Drooling was a great embarrassment and many stopped eating in public because of their rather messy and noisy eating habits. Only one patient was fed through a nasogastric tube and this was during her terminal admission. Gastrostomy was not used in any patient.

Easy fatiguing, fasciculation, and weight loss were great worries to patients and some even suspected that they had something that they regarded as more sinister than motor neurone disease-notably, multiple sclerosis or cancer. Pain was very frequent and became a dominating theme in some patients' lives. It was felt mainly in the neck, back, and limbs and was variously described as diffuse aching, burning, and like an electric shock. Cramp was the major component of pain in seven patients (affecting the legs in five and the arms in one, and being diffuse in one). Pain was often worse at night and was not usually controlled with simple analgesics or anti-inflammatory agents, 20 of 27 patients having abandoned their use because they failed to control symptoms.

Severe falls (defined as resulting in fractures or cuts needing stitches) were a common hazard, especially in the more mobile inde-

TABLE III-Distribution of disability

\begin{tabular}{lrr}
\hline Predominant symptoms & No & $\%$ \\
\hline Minimal disability & 8 & 19 \\
Bulbar & 8 & 19 \\
Arm & 4 & 10 \\
Mobility & 1 & 2 \\
Mixed arm and mobility & 7 & 17 \\
Severe global disability & 14 & 33 \\
\hline
\end{tabular}

TABLE IV-Symptoms and problems in motor neurone disease

\begin{tabular}{|c|c|c|c|c|}
\hline \multirow[b]{2}{*}{ Bulbar } & \multicolumn{2}{|c|}{$\begin{array}{l}\text { All } \\
(n=42) \\
\text { No }\end{array}$} & \multicolumn{2}{|c|}{$\begin{array}{c}\text { Partially and } \\
\text { totally } \\
\text { dependent } \\
\text { (n=22) } \\
\text { No } \%\end{array}$} \\
\hline & & & & \\
\hline $\begin{array}{l}\text { Slurring } \\
\text { Choking } \\
\text { Drooling }\end{array}$ & $\begin{array}{l}28 \\
24 \\
21\end{array}$ & $\begin{array}{l}67 \\
57 \\
50\end{array}$ & $\begin{array}{l}19 \\
16 \\
13\end{array}$ & $\begin{array}{l}86 \\
73 \\
59\end{array}$ \\
\hline \multicolumn{5}{|l|}{ Limb } \\
\hline $\begin{array}{l}\text { Easy fatiguing } \\
\text { Clumsy hands } \\
\text { Severe falls } \\
\text { Fasciculation } \\
\text { Involuntary limb jerks } \\
\text { Leg swelling } \\
\text { Contractures }\end{array}$ & $\begin{array}{r}21 \\
19 \\
17 \\
15 \\
15 \\
8 \\
1\end{array}$ & $\begin{array}{r}50 \\
45 \\
40 \\
36 \\
36 \\
19 \\
2\end{array}$ & $\begin{array}{r}7 \\
6 \\
6 \\
10 \\
9 \\
6 \\
1\end{array}$ & $\begin{array}{r}32 \\
27 \\
27 \\
45 \\
41 \\
27 \\
5\end{array}$ \\
\hline \multicolumn{5}{|l|}{ Miscellaneous } \\
\hline $\begin{array}{l}\text { Frustration and boredom } \\
\text { Pain } \\
\text { Weight loss }>6 \mathrm{~kg} \\
\text { Problem turning at night } \\
\text { Poor sleeping } \\
\text { Constipation } \\
\text { Pressure sores } \\
\text { Urinary disturbance } \\
\text { Depression } \\
\text { Chronic sore throat } \\
\text { Dyspnoea }\end{array}$ & $\begin{array}{r}40 \\
27 \\
18 \\
14 \\
13 \\
8 \\
5 \\
4 \\
3 \\
3 \\
7\end{array}$ & $\begin{array}{r}95 \\
64 \\
43 \\
33 \\
31 \\
19 \\
12 \\
10 \\
7 \\
7 \\
7\end{array}$ & $\begin{array}{r}22 \\
17 \\
9 \\
14 \\
10 \\
7 \\
5 \\
3 \\
1 \\
3 \\
2\end{array}$ & $\begin{array}{r}100 \\
77 \\
41 \\
64 \\
45 \\
32 \\
23 \\
14 \\
5 \\
14 \\
9\end{array}$ \\
\hline
\end{tabular}

pendent group. Constipation requiring regular laxatives or enemas occurred in eight (often due to lack of abdominal muscle power to empty the rectum), two of whom had manual evacuations by their wives.

Swelling of the legs, when it occurred, was always chronic and difficult to control. Raising the legs and elastic stockings appeared to achieve more than diuretics.

Poor sleeping was due to a combination of worry, discomfort, and secretions pooling in the throat (causing choking and drooling). None of the patients had a tracheostomy or used neostigmine like drugs but two had found slight benefit with anticholinergic drugs. Inability to change position at night meant that some needed a change of position every two hours and this appeared to be a major source of deterioration in the spouse's health. Appreciable depression was notably absent; only one patient had been referred to a psychiatrist and only two were taking antidepressants. 


\section{VIEWS ON THE NEUROLOGY CLINIC}

Thirty two patients (including all the totally dependent ones) indicated that they disliked attending the clinic. Many said that they continued attending because they felt it was their only contact with neurological skills. Seriously disabled patients found that the journey was a major ordeal, as was the long wait for transport. Some disliked seeing junior staff and felt inhibited from asking questions. Some thought that they were bevond help and felt guilty about taking up clinic time. If a problem with transport, aids, benefits, or particular symptom crises arose many were unsure about whom to contact. There were also comments about feeling isolated, lack of access to information, and doctors' ignorance about the disease.

\section{AIDS}

Table $\mathrm{V}$ shows the use of aids. Of those who had an aid or adaptation, 14 patients, in the opinion of the interviewer, had clear need of (16) additional aids which had not been provided. This figure rose to 28 when the need for some form of electric turning bed (not currently available) was included.

TABLE V-Aids and adaptations

\begin{tabular}{|c|c|c|c|}
\hline Type & $\begin{array}{l}\text { No (") of } \\
\text { patients with } \\
\text { each aid }\end{array}$ & $\begin{array}{c}\text { No in whom aids } \\
\text { were not } \\
\text { adequate or } \\
\text { appropriate }\end{array}$ & $\begin{array}{c}\text { No who needed } \\
\text { aid now but for } \\
\text { whom it was not } \\
\text { available }\end{array}$ \\
\hline $\begin{array}{l}\text { Wheelchair } \\
\text { Bath aids }\end{array}$ & $15(36)$ & & \\
\hline \multicolumn{4}{|l|}{$\begin{array}{l}\text { Bath aids } \\
\text { Communication aid }\end{array}$} \\
\hline $\begin{array}{l}\text { Electronic } \\
\text { Other }\end{array}$ & $\begin{array}{l}6(14) \\
7(17)\end{array}$ & & 1 \\
\hline Walking frame stick & $9(21)$ & & \\
\hline Collar & $8(19)$ & 5 & 3 \\
\hline Splint & $8(19)$ & 2 & 1 \\
\hline \multicolumn{4}{|l|}{ Lavatory rails seat } \\
\hline Raise & $7(17)$ & 2 & 3 \\
\hline Commode & $4(10)$ & & \\
\hline Ramp & $7(17)$ & & 3 \\
\hline Stair lift & $3(7)$ & 1 & \\
\hline Ball bearing arm support & $3(7)$ & 2 & 1 \\
\hline Hoist & $2(5)$ & & 1 \\
\hline Electric bed & $1(2)$ & & 14 \\
\hline Total & & 12 & $30^{*}$ \\
\hline
\end{tabular}

* 28 patients needed 30 aids

Ten patients had no aids or adaptations of any description and all could have benefited from one or more; one immobile unintelligible individual was confined to a corner of a room without a wheelchair or communicator. Electronic communication aids (usually in the form of a miniprinter) were highly valued and often used in company to avoid accusations of being "drunk" because of even mild slurring of speech.

Collars and splints were owned, but not used, by many. Splints were often uncomfortable. A common problem concerned collars, which were either so tight that they were painful (one man developed a pressure sore on his jaw) or so loose that the chin slipped behind, "trapping" the jaw (three patients). All three of those with an urgent need of a collar appeared to be in imminent danger of trauma to the neck because of a total lack of head control.

Some otherwise useful aids were inadequate because of poor patient fitting-particularly notable were uncomfortable wheelchairs with unsuitable footrests or no headrest. Two patients could not use their ball bearing arm supports; in one case they arrived too late in the disease to be of help and in the other they did not fit the patient's arms.

Thirty two said that they did not know of the Motor Neurone Disease Association. These patients di 1 not appear to differ in any way from those who were aware of the Motor Neurone Disease Association.

\section{HOUSING}

Only two patients were provided with any form of special housing (a granny flat and a warden controlled flat). Fourteen did not have a downstairs lavatory (three of these were totally dependent) and $20 \mathrm{had}$ to use the stairs to get to bed or the lavatory (six of these were partially dependent). Many had to crawl up the stairs for fear of a serious mishap. Only seven had a wheelchair ramp into the house (five of these were totally dependent) and the spouse found that manipu- lating the partner in and out of the house was difficult. Three seriously disabled patients were confined to the house by the absence of a ramp, as their helpers could not manage them on steps.

\section{Discussion}

Initially, we should like to emphasise two points. Firstly, this was not a prevalence study but we have no reason to believe that our patients are atypical or an unusually selected population. Secondly, before we started we seriously considered whether a study of this sort might upset patients and their relatives. Nevertheless, in practice this was not the case and virtually all patients appeared pleased to cooperate in the study and were not distressed by the implications of the questions.

Our study has generated many questions, not all of which can be answered here.

A series of troublesome symptoms have been identified which are only too easy to underestimate or miss, despite their considerable importance to the sufferer. Attention to these undramatic problems may improve the patient's quality of life. Pain is frequent, chronic, and difficult to control with simple analgesics. Its cause in motor neurone disease merits further investigation. There is a good argument for the earlier use of opiates, which are also effective later in the disease. ${ }^{12}$ Severe falls are also frequent and, although the doctor wishes to preserve independence for as long as possible, some patients should probably be advised to convert to a wheelchair existence earlier. Constipation is a good example of an apparently minor symptom, yet a cause of appreciable distress. It would seem sensible to advise regular laxatives (in liquid form if necessary) at an early stage. Manual evacuation should be avoided if possible.

Bulbar problems are among the most distressing in motor neurone disease. These include dysphagia, choking, drooling, and dysarthria. We have not thought it right to embark on measures likely to prolong distress, and no patients were submitted to cricopharyngeal myotomy, gastrostomy, or tracheostomy and only one patient was fed by a nasogastric tube. The ethical problems are considerable but the profession's objective in the late stages of the disease is to minimise suffering and not simply to preserve life. The service provided by the speech therapy department at Frenchay Hospital includes advice and support for those with bulbar problems. Thus patients are seen both routinely and as emergencies arise, and telephone contact is maintained. Several patients spoke enthusiastically about this service.

The provision of aids leaves room for improvement. We found that they are frequently unavailable when needed, or are ineffective. There is a need for remedial therapists to develop specialised skills in providing collars, splints, wheelchairs, and communication aids. A major problem (experienced by one third of patients) is of inability to change position at night. The consequent discomfort means that the spouse has to get up every two to three hours at night to turn the patient, and thus becomes exhausted. There is probably a need for a bed which turns the patient automatically from side to side. The existing beds of this type are large and cannot easily be fitted into the average bedroom. A variety of special beds are, however, available and their use in patients with motor neurone disease should be formally evaluated before a new automatic turning bed is developed.

The doctor should certainly ensure that all patients see an occupational therapist early to avoid an unnecessary wait for an aid or gadget. The need for this can be forecast before it becomes urgent, because it takes time to organise an aid or adaptationand timing is critical with a progressive disorder: it is disheartening for a patient to await an aid, only to find that when it arrives he is no longer able to use it. The decision to supply an aid, of course, requires considerable sensitivity from the doctor and therapist. The premature suggestion that a patient needs a wheelchair might cause unnecessary distress.

A central problem is who should supervise the patient during 
the downhill course of his disease. Whoever this is will require time, patience, and skill. In the present study the patients were mainly supervised in routine neurology clinics. Our policy at Bristol was that $\mathrm{R}$ L-H saw the patient personally at roughly every other visit; nevertheless, some patients indicated that they did not like seeing junior staff at the other visits. It may be argued that the consultant should personally see all patients with motor neurone disease, and as a result of this study R L-H now does this; additionally, he also sees some patients in a joint clinic with the speech therapists. A population of 400000 would be likely to generate 250 cases of multiple sclerosis, and 800 cases of Parkinson's disease. ${ }^{13}$ We have arbitrarily assumed that half of these patients would be appreciably disabled. Shorvon estimates that in the United Kingdom some 150000 epileptics in the community might require regular medical attention. ${ }^{14}$ This gives roughly 1100 such patients in a population of 400000 . If it is assumed that each of the disabled patients suffering with multiple sclerosis or parkinsonism, and the epileptics, require to be seen four times per year in the neurology clinic-this gives about 6500 visits per year, or 125 per week for every week of the year. Moreover, many other disabled patients need to be seen, and these unfortunate people frequently have multiple problems which require considerable time. Clearly the consultant cannot see all these patients personally at every visit. The question of priorities arises and it might be argued that patients with motor neurone disease should not necessarily take precedence over other patients.

What is the role of the general practitioner? The average general practitioner will probably see only one new case of motor neurone disease each 15 years of practice. Thus, whereas his close interest and involvement are clearly desirable, he is unlikely to have the necessary skill to manage the disease effectively.

We suggest that motor neurone disease, along with other disabling neurological diseases, should continue to be supervised in neurology departments. Every effort should be made to achieve some degree of permanence and, if possible, the patient should be seen by the same doctor each time. Severely disabled patients should be seen at home. The consultant would need to remain closely concerned but it might also be possible to use clinical assistants who had received the appropriate training. The requirements for doctors in training clearly need to be considered. Registrars could certainly help at clinics, and, indeed, we think that their training would be enhanced if they were exposed to a high quality service. We suggest also the use of a "key" worker, who might be a nurse or a therapist. This person could act as intermediary and personal agent to the patient, and should be able to speed up the "response time" of the hospital and community resources. $\mathrm{He}$ or she would need wide training in the diverse aspects of the care of motor neurone disease, would work closely with the consultant, and would liaise with the general practitioner and community services. The patient would have his key worker's telephone number and could contact him or her directly, thus reducing delay in receiving help to a minimum. One criticism of any new scheme is that scarce extra resources would be needed. We suggest that such a new model does not necessarily entail more staff, although it may mean redeployment and training of existing staff. The possibility of the key worker being concerned with more than one disease-for example, motor neurone disease and multiple sclerosis-might be considered. A pilot scheme along these lines should be set up.

The classic textbook description of motor neurone disease is incomplete. Conventional neurological symptoms, signs, prognosis, and aetiological speculations are well covered in standard texts ${ }^{15} 16$ but practical management is not. Distressing symptoms and their management are better dealt with in nursing articles ${ }^{3} 4$ and accounts ${ }^{17}$ of personal experience with the disease, which provide excellent insight and education. Accounts of hospice experience ${ }^{12}$ and rehabilitation techniques ${ }^{56}$ emphasise that therapeutic impotence is far from total. An intelligent anticipation of problems should lead to an aid or management "prescription" as precise and effective as drug treatments in other illnesses may be.
Motor neurone disease is a particularly unpleasant disease. No effective treatment is available and the remorseless progression of the disease cannot be stopped. Any system of management is likely to be criticised. None the less we think that there is scope for considerable improvement. The neurologists in this study have a particular interest in disability and yet there are clear deficiencies in the service. We think it likely that things are similar elsewhere in the country. There remains the probability that deficiencies also exist in the management of other chronic disabling conditions such as multiple sclerosis and head injury. There is now an opportunity for the setting up and testing of alternative patterns of care.

We gratefully acknowledge the help of Professor D L McLellan, University Department of Rehabilitation, Southampton; Dr D N Leigh, Wessex Neurological Centre, Southampton; Dr P M Enderby, Frenchay Hospital, Bristol; and Mrs M Holbrook, Bristol Stroke Unit.

\section{References}

1 Carus R. Motor neurone disease : a demeaning illness. Br Med f 1980;280:455-6. Rosin AJ. The problems of motor neurone disease. Age Ageing 1976;5:37-42. Blount M, Bratton C, Luttrell N. Management of the patient with amyotrophic lateral sclerosis. Nurs Clin North Am 1979;77:1-3

Summers DH. Motor neurone disease. Nurs Times $1981 ; 77: 1-3$

Sinaki M, Mulder DW. Rehabilitation techniques for patients with amyotrophic lateral sclerosis. Mayo Clin Proc 1978;53:173-8.

Campbell MJ. Management of patients with motor neurone disease. Int Rehab Med 1980;2:111-5

Norris FH, Denys EH, Lebo CP. Surgery in patients with amyotrophic lateral Amsterdam: experience with cricopharyngeal myotomy in 100 cases (abstract). 8 Gonzalez JB, Aronson AE. Palatal lift prosthesis for treatment of anatomic and neurologic palatopharyngeal insufficiency. Cleft Palate $\mathcal{f} 1970 ; 7: 91-104$.

9 Lehner WE, Ballard IM, Figueroa WG, Stratton Woodruff D. Home care utilizing a ventilator in a patient with amyotrophic lateral sclerosis. $\mathcal{f} \mathrm{Fam}$ Pract 1980;10:39-42.

10 Donaldson SW, Wagner CC, Gresham GE. A unified ADL evaluation form. Arch Phys Rehab 1973 April:175-9.

11 Enderby PM. Frenchay dysarthria assessment. San Diego: College-Hill Press, 1983.

12 Saunders C, Summers DH, Teller N. Hospice-the living idea. London: Edward Arnold, 1981:126-47.

13 Kurtzke JF. The current neurologic burden of illness and injury in the United States. Neurology 1982;32:1207-14.

14 Shorvon SD. Specialized services for the non-institutionalized patient with 15 Walton J. Disorders of voluntary muscle. 4th ed. London: Churchill Livingstone 1981 .

16 Rose C. Clinical neuroepidemiology. London: Pitman Medical, 1980.

17 Henke E. Motor neurone disease-a patient's view. Br Med $\mathcal{f} 1968 ; 4: 765-6$.

\section{APPENDIX-Scale for disability in motor neurone disease}

\begin{tabular}{|c|c|}
\hline (A) Bulbar function & $\begin{array}{l}\text { Some help needed } 1 \\
\text { Dependent } 0\end{array}$ \\
\hline $\begin{array}{l}\text { Swallowing: } \\
\text { Normal } 3 \\
\text { Chokes occasionally } 2 \\
\text { Chokes regularly } 1 \\
\text { Nasogastric tube } 0\end{array}$ & $\begin{array}{l}\text { Mobility: } \\
\text { Independent for } 50 \text { metres } \pm \text { an } \\
\text { aid } 3 \\
\text { As above but needs help of } 1 \\
\text { person } 2\end{array}$ \\
\hline 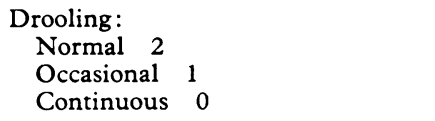 & $\begin{array}{l}\text { Independent with wheelchair } 1 \\
\text { Immobile } 0 \\
\text { Stairs: } \\
\text { Independent } 2\end{array}$ \\
\hline $\begin{array}{l}\text { Speech: } \\
\text { Normal } 2 \\
\text { Slurs 1 } \\
\text { Unintelligible } 0\end{array}$ & $\begin{array}{l}\text { Manages with help } 1 \\
\text { Unable } 0 \\
\text { Grooming: } \\
\text { Independent } 1 \\
\text { Dependent } 0\end{array}$ \\
\hline (B) Limb function & $\begin{array}{l}\text { Bed-chair transfer: } \\
\text { Independent } 3\end{array}$ \\
\hline $\begin{array}{l}\text { Bathing: } \\
\text { Independent } 1 \\
\text { Dependent } 0\end{array}$ & $\begin{array}{l}\text { Manages with minimal help } 2 \\
\text { Needs major help } 1 \\
\text { Has to be lifted } 0 \text { Top score } 15\end{array}$ \\
\hline $\begin{array}{l}\text { Dressing: } \\
\text { Independent } 2 \\
\text { Needs some help } 1 \\
\text { Dependent } 0\end{array}$ & (C) Care source: \\
\hline $\begin{array}{l}\text { Feeding: } \\
\text { Independent or manages most } 1 \\
\text { Dependent } 0\end{array}$ & $\begin{array}{l}\text { Independent } 3 \\
\text { Help from family } 2 \\
\text { Outside help } 1\end{array}$ \\
\hline $\begin{array}{l}\text { Toilet: } \\
\quad \text { Independent } 2\end{array}$ & $\begin{array}{l}\text { Regular holiday relief } 0 \\
\text { Top score } 3\end{array}$ \\
\hline
\end{tabular}

